\title{
A NUMERICAL AND EXPERIMENTAL STUDY OF WAVY ICE STRUCTURE IN A PARALLEL PLATE CHANNEL
}

\author{
B. WEIGAND, H. BEER \\ Institut fur Technische Thermodynamik \\ Technische Hochschule Darmstadt \\ Petersenstraße 30, 6100 Darmstadt, Germany
}

\begin{abstract}
The paper presents a numerical model for predicting steady-state ice formation inside a cooled, parallel plate channel. The study takes into account the strong interactions occuring between the turbulent flow, the shape of the ice and the heat transfer at the ice-water interface, which lead to the formation of wavy ice layers. The presented model is found to be able to predict realistic variations of the ice layer thickness for a wide range of Reynolds numbers and cooling parameters. The numerical results were verified by comparing with own measurements and good agreement was found.
\end{abstract}

\section{Introduction}

Ice formation phenomena of flowing water in a pipe or a channel whose wall is kept at a uniform temperature below the freezing temperature of the water, is a basic engineering problem. It introduces many practical problems, such as pressure drop, diminution of flow rates and sometimes, breakage of the pipe as a result of flow blockage by ice. The phenomenon of freezing of flowing water involves interactions between the turbulent flow, the shape of the ice layer and the heat transfer at the ice-water interface. Under certain conditions these interactions result in an instability of the ice layer. This instability is caused by the strong laminarization of the turbulent flow due to converging ice layers in the entrance region of the cooled test section and results in a wavy ice structure. Wavy ice layers with one wave, occuring in a parallel plate channel, were investigated experimentally by Seki [1] and by Weigand and Beer [2]. No numerical treatment of the conservation equations concerning this type of ice layers was performed in the past because of the complexity of the problem. Therefore, the subject of this paper is the presentation of a numerical calculation of the steady-state ice layers with one wave. The numerical study is supported by a detailed experimental investigation.

\section{Analysis}

Consideration is given to a turbulent flow entering a cooled parallel plate channel (Fig. 1) with a fully developed velocity profile and with the uniform temperature $T_{0}$. In the chill region, the wall temperature is maintained at a constant value $T_{w}$, which is below the freezing temperature $T_{\mathrm{F}}$ of the fluid and a frozen layer is generated at the cooled walls. Assuming an incompressible, Newtonian fluid with constant fluid properties, the steady-state boundary layer 


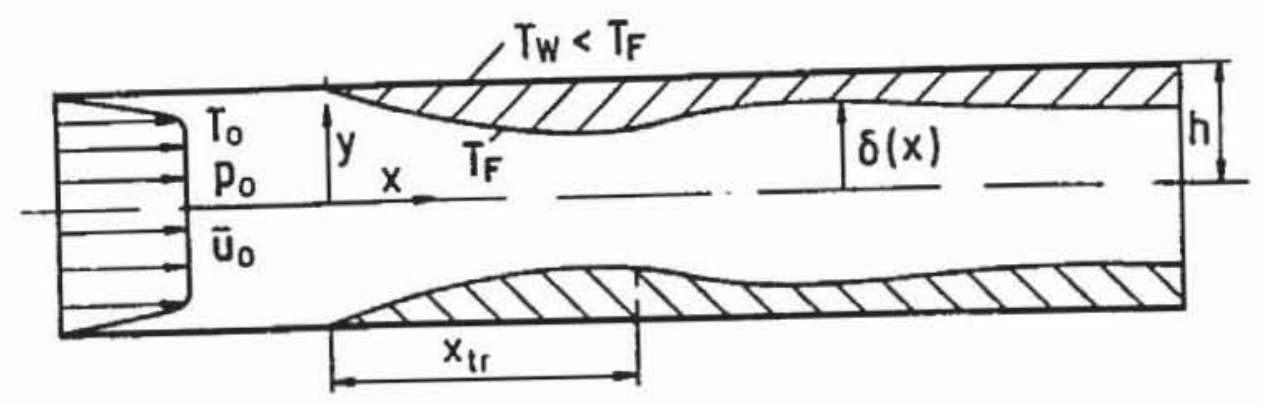

Figure 1. Physical model and coordinate system.

equations for the fluid can be written as [3]

$$
\begin{aligned}
& \frac{\partial u}{\partial x}+\frac{\partial v}{\partial y}=0 \\
& u \frac{\partial u}{\partial x}+v \frac{\partial u}{\partial y}=-\frac{\partial p}{\partial x}+v_{L} \frac{\partial}{\partial y}\left[\left(1+\varepsilon_{m}^{*}\right) \frac{\partial u}{\partial y}\right] ; \quad 0=-\frac{\partial p}{\partial y} \\
& u \frac{\partial T}{\partial x}+v \frac{\partial T}{\partial y}=a_{L} \frac{\partial}{\partial y}\left[\left(1+\frac{P_{r}}{P_{r_{t}}} \varepsilon_{m}^{*}\right) \frac{\partial T}{\partial y}\right]
\end{aligned}
$$

where $\varepsilon_{\dot{m}}=\varepsilon_{\mathrm{m}} / v_{\mathrm{L}}$ is the eddy viscosity and $\mathrm{Pr}_{\mathrm{t}}$ is the turbulent Prandtl number according to Cebeci [3]. In the solid region, one dimensional heat conduction is assumed. Therefore, the temperature distribution in the solid crust can be shown to be

$$
\left(\mathrm{T}_{\mathrm{s}}-\mathrm{T}_{\mathrm{p}}\right) /\left(\mathrm{T}_{\mathrm{w}}-\mathrm{T}_{\mathrm{p}}\right)=(\mathrm{y}-8) /(\mathrm{h}-8) ; 8<\mathrm{y}<\mathrm{h}
$$

Eqs. (1) are coupled with eq. (2) by the interface energy equation

$$
\mathrm{k}_{\mathrm{z}} \partial \mathrm{T}, / \partial \mathrm{y}=\mathrm{k}_{\mathrm{L}} \partial \mathrm{T} / \partial \mathrm{y} ; \mathrm{y}=\mathbf{8}
$$

Deissler [4] found out that the turbulent Reynolds shear stress can be taken approximately as constant along a streamline in a highly accelerated flow, which yields a "laminarization"

$$
\overline{u^{\prime} v^{\prime}}(\Psi)=\left(\overline{u^{\prime} v^{\prime}}(\Psi)\right)_{x=0} \quad, \quad \Psi=\text { const. }
$$

where $\psi$ is the streamfunction defined in the usual way [3]. Equation (4) was used for calculating $\varepsilon_{\mathrm{m}}$ in the region $0 \leq \mathrm{x} \leq \mathrm{x}_{\mathrm{tr}}$. The initial distribution of the turbulent shear stress for $x=0$ can easily be obtained with the help of a mixing length theory [3].

For $x>x_{t r}$ the acceleration due to converging ice layers ceases and the flow recedes to its originally turbulent state. In this region, where the heat transfer at the solid-liquid interface is strongly enhanced, the eddy viscosity was calculated with a modified mixing length model according to Moffat and Kays [5]. The transition point $x_{t r}$ was correlated from measurements. For more detailed informations concerning the turbulence modelling, the reader is refered to [6. The calculation of the frozen layer involves an iteration procedure. Initially a distribution of the ice layer is assumed. With this variation of $\delta(x)$ the conservation equations (1) are solved with the help of an implicit finite-difference method, which is known in literature as 
the Keller box-method [3]. After solving the eqs. (1), a new distribution of $8(x)$ is calculated by inserting the yet known temperature gradient at the solid-liquid interface into eq. (4). This iteration process is repeated until $\Delta 8=\left|\mathrm{8}^{(\mathrm{i})}-\mathrm{8}^{(\mathrm{i}-1)}\right|<0.01 \mathrm{~h}$ at every axial position for two successive iterations.

\section{Results and Discussion}

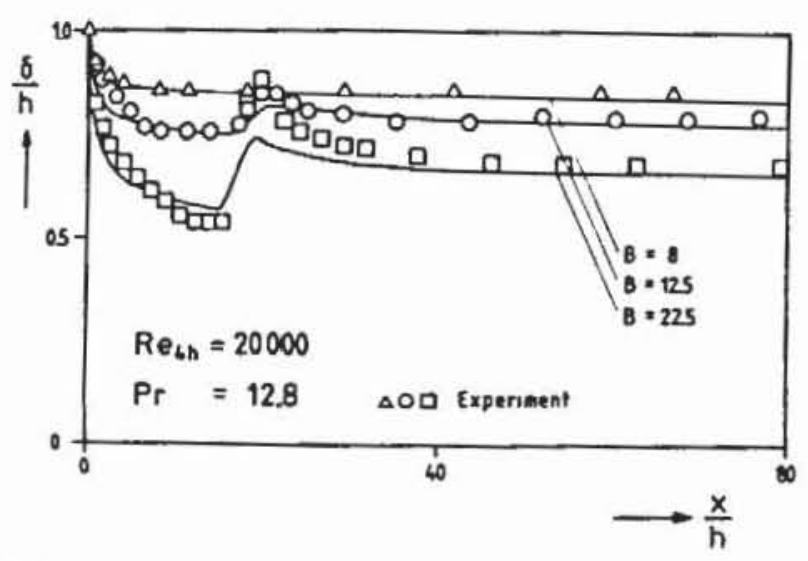

Figure 2. Influence of the cooling parameter $B$ on the shape of the ice layers.

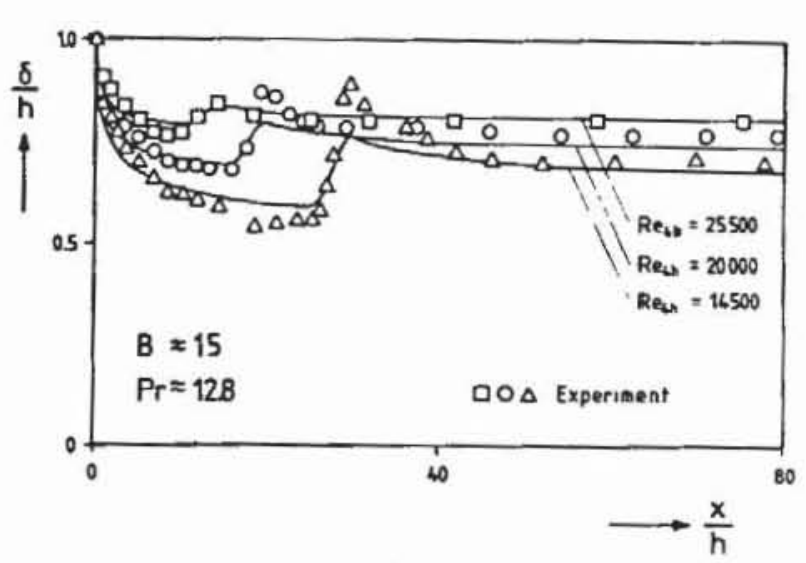

Figure 3. Influence of the Reynolds number on the shape of the ice layers.

Fig. 2 and Fig. 3 show comparisons between calculated and measured ice layers, plotted as a function of the axial coordinate. Fig 2 elucidates that an increasing wall cooling parameter $\mathrm{B}=\mathrm{k}_{\mathrm{s}} / \mathrm{k}_{\mathrm{L}}\left(\mathrm{T}_{\mathrm{F}}-\mathrm{T}_{\mathrm{w}}\right) /\left(\mathrm{T}_{0}-\mathrm{T}_{\mathrm{F}}\right)$ results in a thicker ice layer for a given value of the Reynolds number $\mathrm{Re}_{4 \mathrm{~h}}=\overline{\mathrm{u}}_{0} 4 \mathrm{~h} / \mathrm{v}_{\mathrm{L}}$ (where $\overline{\mathrm{u}}_{0}$ denotes the axial mean velocity at the entrance of the test section). From Fig. 2 it can be seen that the distance $x_{t r}$ between the entrance of the chill region and the point for which the ice layer reaches its maximum thickness, seems to be only a function of the Reynolds number. Fig. 3 visualizes the effect of a variation in Reynolds number on the ice layer thickness for a fixed value of B. It must be stated that an increasing Reynolds number results in a decreasing ice layer thickness. This is due to the intensified heat transfer from the flowing liquid to the solidified crust with growing values of $\mathrm{Re}_{4 \mathrm{~h}}$. As can be observed from Figs. 2 - 3, the agreement between theory and experiment is quite good.

\section{References}

1. Seki, N., Fukusako, S. and Younan, G.W. (1984) 'Ice formation phenomena for water flow between two cooled parallel plates', J. Heat Transfer 106, 498 - 505.

2. Weigand, B. and Beer, H. (1991) 'The morphology of ice structure in a parallel plate channel', Proc. 3th Int. Symp. on Cold Regions Heat Transfer, Fairbanks, 167 - 176.

3. Cebeci, T. and Bradshaw, P. (1984) Physical and computational aspects of convective heat transfer, Springer, New York.

4. Deissler, R.G. (1974) 'Evolution of a moderately short turbulent boundary layer in a severe pressure gradient', J. Fluid Mech. 64, 763 - 774.

5. Moffat, R.J. and Kays, W.M. (1984) 'A review of turbulent boundary layer heat transfer research at Stanford, 1958 - 1983,' Adv. in Heat Transfer 16, 242 - 366.

6. Weigand, B. (1992) Erstarrungsvorgänge einer strömenden Flüssigkeit in einem ebenen, geraden Kanal, Doctoral Thesis, TH Darmstadt 